\title{
Mountain wave PSC dynamics and microphysics from ground-based lidar measurements and meteorological modeling
}

\author{
J. Reichardt ${ }^{1,2, ~ *}$, A. Dörnbrack ${ }^{3}$, S. Reichardt ${ }^{1,2}$, P. Yang ${ }^{4}$, and T. J. McGee ${ }^{2}$ \\ ${ }^{1}$ Joint Center for Earth Systems Technology, University of Maryland Baltimore County, Baltimore, Maryland, USA \\ ${ }^{2}$ Atmospheric Chemistry and Dynamics Branch, NASA Goddard Space Flight Center, Greenbelt, Maryland, USA \\ ${ }^{3}$ Institut für Physik der Atmosphäre, Deutsches Zentrum für Luft- und Raumfahrt (DLR) Oberpfaffenhofen, Weßling, \\ Germany \\ ${ }^{4}$ Department of Atmospheric Sciences, Texas A\&M University, College Station, Texas, USA \\ *now at: Meteorologisches Observatorium Lindenberg, Deutscher Wetterdienst, Tauche, Germany
}

Received: 20 August 2003 - Published in Atmos. Chem. Phys. Discuss.: 18 November 2003

Revised: 22 April 2004 - Accepted: 23 July 2004 - Published: 30 July 2004

\begin{abstract}
The day-long observation of a polar stratospheric cloud (PSC) by two co-located ground-based lidars at the Swedish research facility Esrange $\left(67.9^{\circ} \mathrm{N}, 21.1^{\circ} \mathrm{E}\right)$ on 16 January 1997 is analyzed in terms of PSC dynamics and microphysics. Mesoscale modeling is utilized to simulate the meteorological setting of the lidar measurements. Microphysical properties of the PSC particles are retrieved by comparing the measured particle depolarization ratio and the PSC-averaged lidar ratio with theoretical optical data derived for different particle shapes. In the morning, nitric acid trihydrate (NAT) particles and then increasingly coexisting liquid ternary aerosol (LTA) were detected as outflow from a mountain wave-induced ice PSC upwind Esrange. The NAT PSC is in good agreement with simulations for irregularshaped particles with length-to-diameter ratios between 0.75 and 1.25 , maximum dimensions from 0.7 to $0.9 \mu \mathrm{m}$, and a number density from 8 to $12 \mathrm{~cm}^{-3}$ and the coexisting LTA droplets had diameters from 0.7 to $0.9 \mu \mathrm{m}$, a refractive index of 1.39 and a number density from 7 to $11 \mathrm{~cm}^{-3}$. The total amount of condensed $\mathrm{HNO}_{3}$ was in the range of 8 $12 \mathrm{ppbv}$. The data provide further observational evidence that NAT forms via deposition nucleation on ice particles as a number of recently published papers suggest. By early afternoon the mountain-wave ice PSC expanded above the lidar site. Its optical data indicate a decrease in minimum particle size from 3 to $1.9 \mu \mathrm{m}$ with time. Later on, following the weakening of the mountain wave, wave-induced LTA was observed only. Our study demonstrates that ground-based lidar measurements of PSCs can be comprehensively interpreted if combined with mesoscale meteorological data.
\end{abstract}

Correspondence to: J. Reichardt

(Jens.Reichardt@dwd.de)

\section{Introduction}

Mountain wave-induced PSCs constitute an ideal natural laboratory to investigate the formation and dissipation of cloud particles. Under quasi-stationary meteorological conditions these mesoscale clouds do not strongly vary their spatial position relative to the ground, and in the air flowing through them particles nucleate, grow, and evaporate continuously over a period of hours. Previously, particle evolution in wave PSCs was successfully studied based on quasi-Lagrangian observations acquired with airborne lidars (Carslaw et al., 1998; Tsias et al., 1999; Wirth et al., 1999; Dörnbrack et al., 2002; Hu et al., 2002; Fueglistaler et al., 2003). A similar study that rests upon data obtained with ground-based lidars has not been published so far, probably mainly due to the fact that they lack the additional dimension that is offered by aircraft observations. This limitation makes ground measurements particularly difficult to interpret because one cannot distinguish between microphysical and dynamical processes without auxiliary information. In this contribution, such a study is presented for the first time using mesoscale model simulations to resolve the ambiguity of the ground-based lidar observations.

In winter 1996/1997 the lidars of the GKSS Research Center (GKSS Raman lidar; Reichardt et al., 1996) and of the University of Bonn (U. Bonn lidar; Müller et al., 1997) were operated at Esrange as part of an international campaign dedicated to investigations of dynamically induced regionalscale PSCs in the lee of the Scandinavian mountains (Fricke, 1997). In the morning of 16 January 1997, increasing northwesterly tropospheric wind flow over the Scandinavian mountain ridge excited gravity waves propagating into the stratosphere and generating temperature minima eventually 
low enough for nucleation of solid particles. This mountain wave PSC event, possibly the strongest that winter (Dörnbrack et al., 2001), lasted the whole day until wave activity ceased in the evening. Because of favorable tropospheric weather conditions the two Esrange lidars could monitor the PSC system without interruption. This unique data set is presented here, and an analysis in terms of PSC dynamics and microphysics is given.

The article is organized as follows. Section 2 is a description of the lidar instruments and of the measurement techniques used for the determination of the PSC optical properties. In Sect. 3, the meteorological situation on 16 January 1997 is discussed, and the results of the mesoscale model are presented. In Sect. 4, a macrophysical interpretation of the lidar observations is given that is based on the mesoscale numerical simulation and on the PSC optical characteristics. Section 5 focuses on the microphysical analysis of selected time periods during the PSC development. For the first time, microphysical properties of crystalline PSC particles are retrieved assuming polyhedral particle shapes. Section 6 is a summary.

\section{Instrumentation and data analysis}

\subsection{GKSS Raman lidar}

The GKSS Raman lidar is a polarization Raman DIAL for nighttime measurements of clouds, water vapor (troposphere only), and ozone (Reichardt et al., 1996). In January 1997 this mobile system was operated at Esrange, the emitted laser wavelengths were 308 and $355 \mathrm{~nm}$. PSC optical properties (including depolarization ratio) are determined at $355 \mathrm{~nm}$. No effort was made to retrieve PSC properties at the shorter wavelength because absorption by ozone molecules poses a problem for the data analysis of thin PSCs here. In what follows a description of the analysis techniques that pertain to the GKSS Raman lidar data is given.

\subsubsection{Backscatter ratio}

Backscatter ratio $R$ (ratio of total to molecular backscattering) is determined by forming the ratio of an elasticbackscatter lidar signal to the corresponding vibrationalrotational Raman signal (molecular nitrogen), and calibrating it at heights with negligible particle scattering. Backscatter ratio is a useful parameter for studies of PSC dynamics, however, it is less helpful in the retrieval of particle shapes and sizes because it depends on the particle number density (Reichardt et al., 2002c). This is not the case of the extinction-tobackscatter (lidar) ratio and the particle depolarization ratio.

\subsubsection{Particle depolarization ratio}

Particle depolarization ratios $\left(\delta_{\text {par }}\right.$, subscript 'par' denotes 'particle') are determined by use of the conventional two- signal technique of Schotland et al. (1971). Depolarization measurements with this technique have to be calibrated. In our case, this was done by fitting the depolarization-ratio profile obtained for the 16 January 1997 ice PSC between 16:55 and 17:55 UT to the one determined for the same time period with a new three-signal method for depolarization measurements (Reichardt et al., 2003). This approach to calibration is accurate because it is largely insensitive to experimental errors, and no critical assumptions about the atmospheric depolarization ratio at some reference height have to be made. Finally, to obtain $\delta_{\mathrm{par}}$, the calibrated polarization data are corrected for the influence of molecular scattering which depresses the measured depolarization ratio in optically thin PSCs and at cloud boundaries below the value of light scattered by the PSC particles alone. For a discussion of statistical and systematic errors see Reichardt et al. (2002a).

\subsubsection{PSC-averaged lidar ratio}

Lidar-ratio $\left(S_{\mathrm{par}}\right)$ data have proven valuable in microphysical studies of tropospheric clouds (Reichardt et al., 2002b), and show great potential in PSC investigations (Reichardt et al., 2002c). In order to have $S_{\text {par }}$ information available for the PSC under investigation, we calculate the PSC-layer mean value of $S_{\mathrm{par}}, \bar{S}_{\mathrm{par}}$, as PSC optical depth $\tau$ divided by integrated PSC backscatter coefficient (lidar-ratio profiles cannot be determined because of insufficient Raman signal strength above $\sim 20 \mathrm{~km}$ ). The (integrated) backscatter coefficient is obtained with the Raman-lidar technique (Ansmann et al., 1992). The optical depth of the PSC can be calculated according to

$\tau=\ln \left[N\left(z_{\mathrm{b}}\right) / N\left(z_{\mathrm{t}}\right)\right] / 2$,

where $N\left(z_{\mathrm{b}}\right)$ and $N\left(z_{\mathrm{t}}\right)$ is the elastic lidar signal at heights below and above the PSC, respectively. Before $\tau$ is calculated, $N$ is corrected for background, range, and for backscattering and extinction by molecules. Radiosonde data of the measurement night are used to determine the atmospheric density profile required for the correction of molecular scattering. The residual, absolute systematic errors in $\bar{S}_{\text {par }}$ that result from this Rayleigh correction are the larger the smaller the PSC optical depth. However, since the latter is often anticorrelated with lidar ratio (optically thin mountain wave PSCs consist of small particles with high $S_{\text {par }}$ ), the $\bar{S}_{\text {par }}$ uncertainty can be estimated to be $\sim 20 \%$ for all PSC measurements considered here. Obviously, $\bar{S}_{\text {par }}$ is the more meaningful the smaller the altitude variations in particle optical properties are. In our analysis we have used the other particle optical property measured, $\delta_{\mathrm{par}}$, as an indicator of PSC variability.

\subsubsection{Polarization-sensitive backscatter ratios}

Recent analyses of lidar measurements suggest that scattering by both solid and liquid particles may contribute significantly to the optical properties of low-backscatter (type-I, 
according to the classification of Browell et al., 1990) PSCs (e.g. Gobbi et al., 1998; Stein et al., 1999; Toon et al., 2000; Biele et al., 2001). In this case, the interpretation of the PSC data in terms of the two coexisting particle classes can be improved if backscatter coefficients (or backscatter ratios) are studied separately for both states of polarization, since droplet scattering adds to the parallel-polarized lidar signal alone (single scattering assumed) whereas the light backscattered from nonspherical solid particles has both parallel- and perpendicular-polarized components. Our discussion of the type-I PSCs on 16 January 1997 includes an analysis that is similar to these previous studies, but in order to avoid calibration problems we look at the two quantities $B^{\|}$and $B^{\perp}$, the ratios of, respectively, parallel-polarized and perpendicularpolarized particle backscatter coefficients to the backscatter coefficient of molecular scattering. $B^{\|}$and $B^{\perp}$ are calculated from the $R$ and $\delta_{\text {par }}$ measurements according to

$B^{\|}=(R-1) /\left(1+\delta_{\mathrm{par}}\right)$,

$B^{\perp}=\delta_{\mathrm{par}}(R-1) /\left(1+\delta_{\mathrm{par}}\right)$.

Obviously, $B^{\|}$and $B^{\perp}$ contain the same information as $R$ and $\delta_{\text {par }}$ but some aspects of PSC scattering are easier discerned if one or the other pair of variables is used.

\subsection{U. Bonn lidar}

The U. Bonn lidar at Esrange is a polarization Raman lidar, operating at a wavelength of $532 \mathrm{~nm}$ at the time of the measurements discussed here. Daylight capabilities existed for the parallel-polarized elastic return signal (Müller et al., 1997). These data are used in this study to visualize the development of the macrophysical PSC properties during daytime.

\subsection{On the effect of multiple scattering}

On 16 January 1997, optically thin tropospheric ice clouds were present above the lidar site, sporadically before and continuously after $\sim 20: 00$ UT, respectively (Fricke et al., 1999). For that reason, the effect of multiple scattering in cirrus clouds on the PSC observations is briefly addressed in the following, since it might be seen as a possible source of error in the determination of PSC optical properties, particularly $\delta_{\text {par }}$. We show that the multiple-scattering effect is negligible. We employed the multiple-scattering model described by Reichardt et al. (2000a) and Reichardt (2000) to simulate the multiple-scattering contributions to the elastic lidar return signals from the stratosphere. The cirrus extinction profile measured around 22:26 UT with the GKSS Raman lidar, and lidar parameters of this instrument were chosen for the simulations. Model results are shown in Fig. 1. Second-order scattering is the dominant multiple-scattering effect, it contributes $<\sim 4 \%$ to the total lidar signal above $20 \mathrm{~km}$. Since doubly scattered light experienced a single (direct) forward-scattering process in the cirrus cloud that does
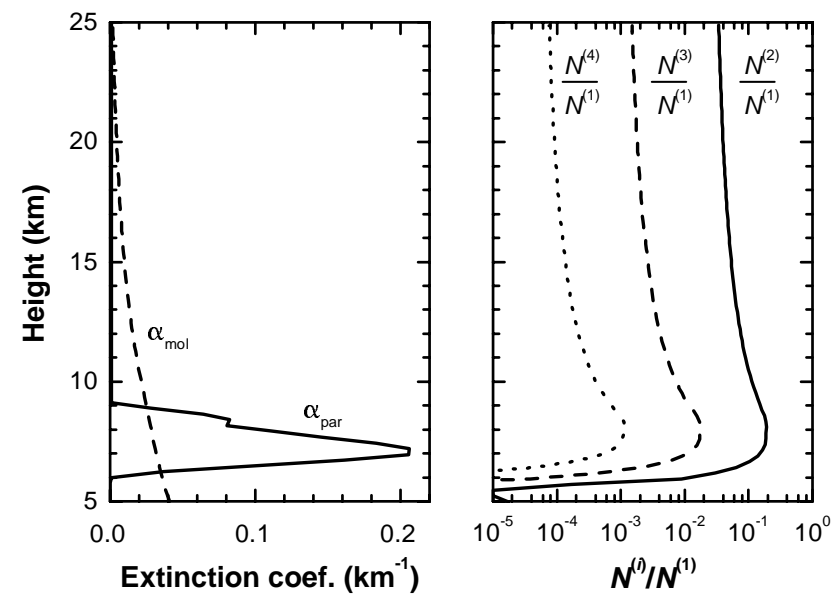

Fig. 1. Cirrus extinction profile ( $\alpha_{\text {par }}$; observed over Esrange on 16 January 1997 between 22:06 and 22:46 UT), and molecular extinction $\left(\alpha_{\text {mol }}\right.$; 16 January 1997 radiosonde data) (left), and modeled ratios of multiply to singly scattered light (right). For the multiple-scattering calculations the cirrus cloud is assumed to consist of columnar crystals with maximum dimensions between 20 and $700 \mu \mathrm{m}$; the laser wavelength is $355 \mathrm{~nm}$; and the lidar field of view is $0.6 \mathrm{mrad}$.

not change the state of polarization, this signal augmentation does not affect the depolarization measurement in PSCs. Only backscattered light of higher scattering orders (two or more scattering processes in the cirrus clouds) might interfere with the $\delta_{\text {par }}$ determination, however, they are irrelevant in our case (scattering orders $>2$ amount to less than $0.2 \%$ above $20 \mathrm{~km}$ ). Finally, we want to point out that multiple scattering in cirrus clouds does not play a role in measurements of PSC backscatter and lidar ratios either, because, respectively, the multiple-scattering contributions to elastic and Raman return signals cancel out (Wandinger, 1998), and the ratios of multiply to singly scattered light depend only weakly on height in the stratosphere.

\section{Meteorological setting}

Results of a mesoscale model simulation illustrate the meteorological setting. The mesoscale fields are calculated with the non-hydrostatic weather prediction model MM5-version 3.4 (Dudhia, 1993; Dudhia et al., 2001). The outer model domain is centered at $\left(65^{\circ} \mathrm{N}, 20^{\circ} \mathrm{E}\right)$ with an extension of $2457 \mathrm{~km} \times 2457 \mathrm{~km}$. In this domain a horizontal grid size of $\Delta x=27 \mathrm{~km}$ is used. A local grid refinement scheme (nested domains of 9 and $3 \mathrm{~km}$ horizontal resolution, respectively) is applied to resolve most of the horizontal wavenumber spectrum of vertically propagating gravity waves excited by the orography.

The mesoscale simulation presented in this paper was performed with 128 vertical levels up to the model top at $10 \mathrm{hPa}(\sim 30 \mathrm{~km})$ which results in a high spatial resolution 

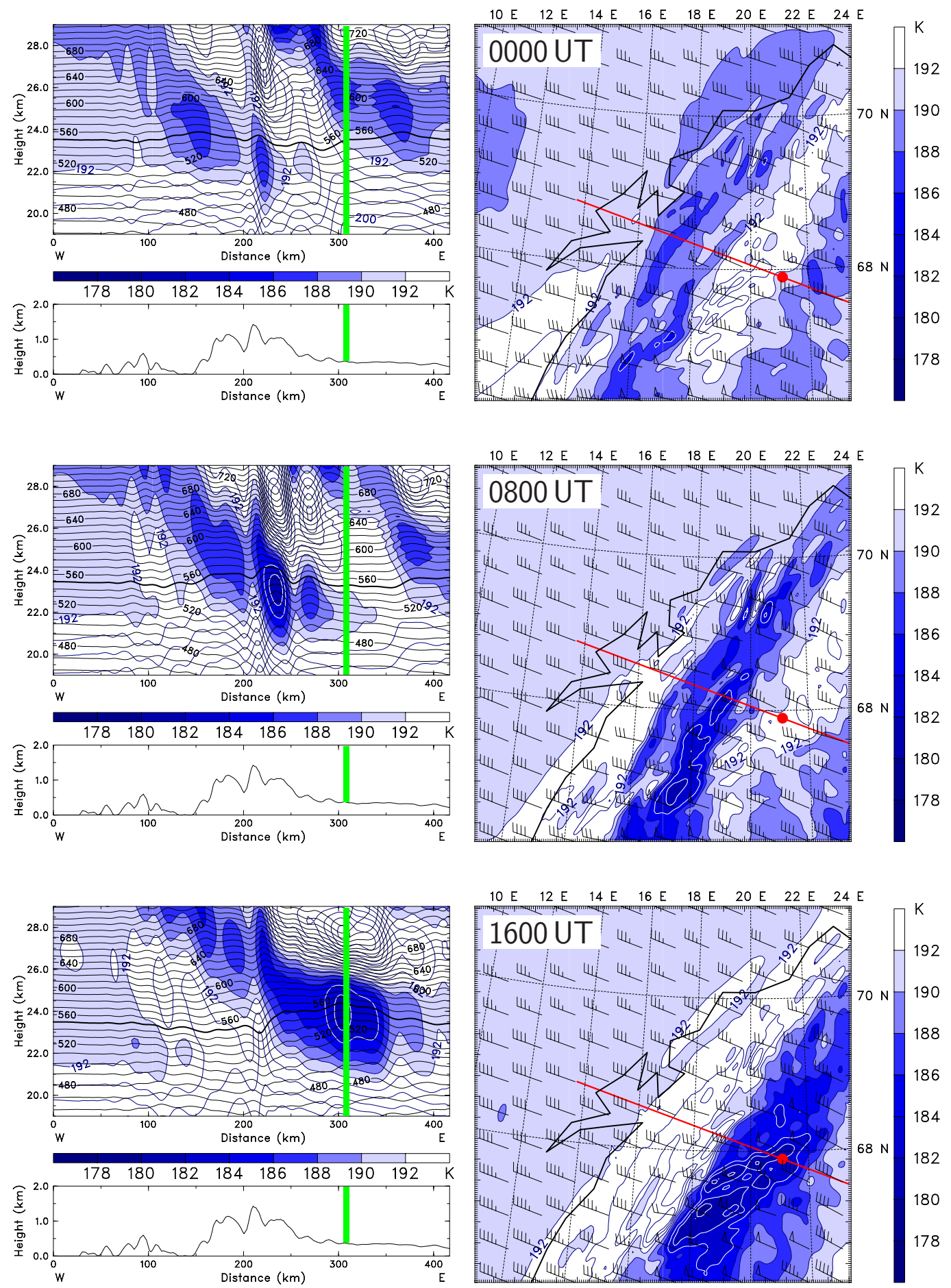

Fig. 2. Temperature $T \leq 192 \mathrm{~K}$ (color shaded; $\mathrm{K}$ ) at the $550-\mathrm{K}$ isentropic surface (right) and along the vertical section as indicated by the red line (left) on 16 January 1997. Additional fields on the right: horizontal wind vectors (barbs; long: $10 \mathrm{~ms}^{-1}$, short: $5 \mathrm{~ms}^{-1}$ ) and $T \leq 184 \mathrm{~K}$ (white lines; $\Delta T=2 \mathrm{~K}$ ). On the left: potential temperature $\Theta$ (solid black lines; $\Delta \Theta=10 \mathrm{~K}, 550-\mathrm{K}$ isentrope bold) and temperature (solid blue lines; $\Delta T=2 \mathrm{~K}$ ); here again, white lines mark regions with $T \leq 184 \mathrm{~K}$. The position of the lidar site at Esrange is marked (red dot in the horizontal and thick green line in the vertical section). The profile of the model orography is plotted below each vertical section. Numerical results are from the innermost domain of the mesoscale model $(\Delta x=3 \mathrm{~km})$. 

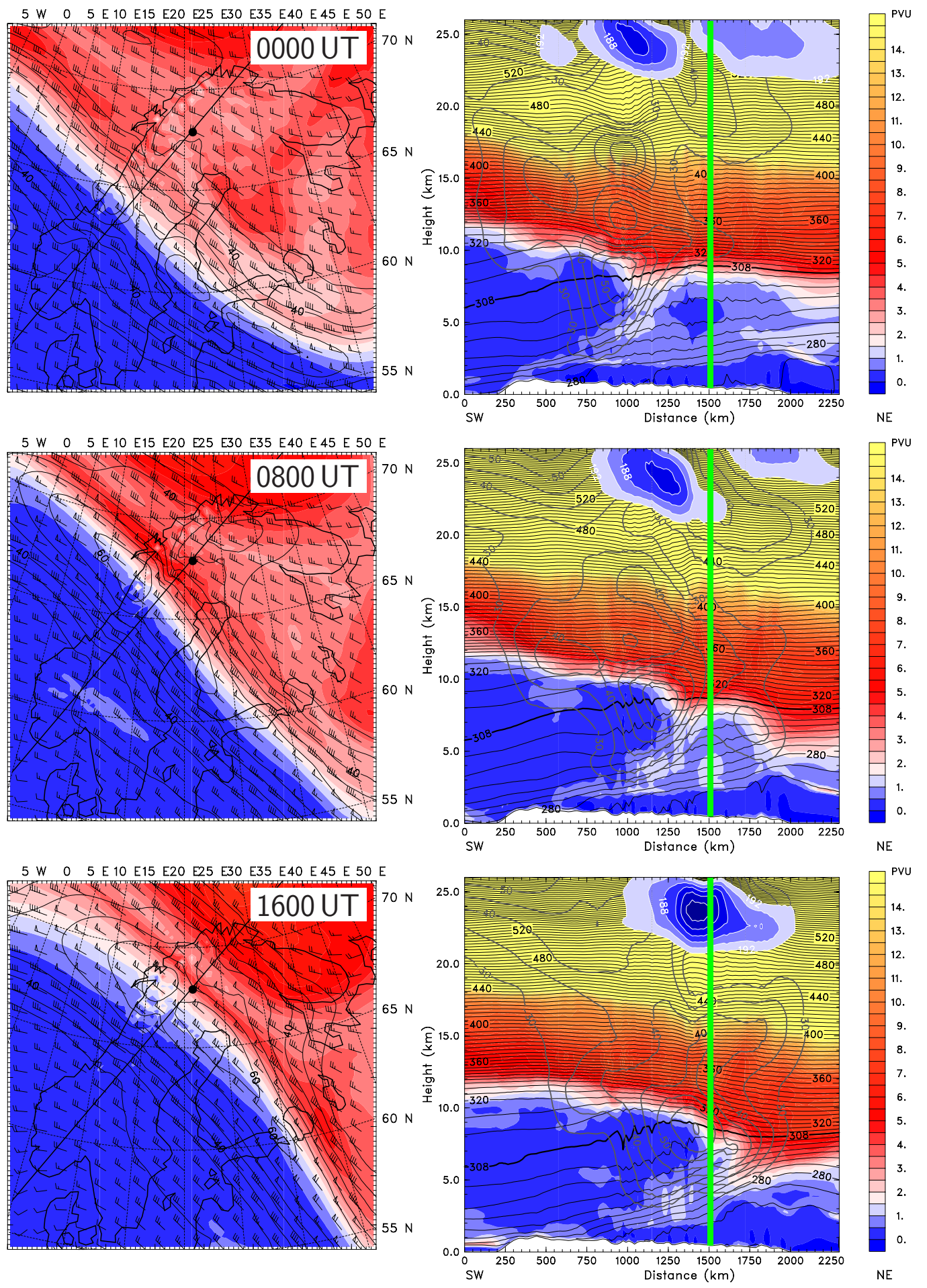

Fig. 3. Potential vorticity (color shaded; PVU, where $1 \mathrm{PVU}=10^{-6} \mathrm{~K} \mathrm{~m}^{2} \mathrm{~kg}^{-1} \mathrm{~s}^{-1}$ ) on the $308-\mathrm{K}$ isentropic surface (left) and along the vertical section as indicated by the black line (right) on 16 January 1997. Additional fields on the left: horizontal wind vectors (barbs; long: $10 \mathrm{~ms}^{-1}$, short: $5 \mathrm{~ms}^{-1}$ ) and horizontal wind speed $>40 \mathrm{~ms}^{-1}$ (black solid lines; $5 \mathrm{~ms}^{-1}$ increment). On the right: potential temperature $\Theta$ (thin black solid lines; $\Delta \Theta=4 \mathrm{~K}, 308-\mathrm{K}$ isentrope bold), horizontal wind speed $>40 \mathrm{~ms}^{-1}$ (thick solid lines; $5 \mathrm{~ms}{ }^{-1}$ increment), and stratospheric temperature $T \leq 192 \mathrm{~K}$ (color shaded as in Fig. 2 for heights $>20 \mathrm{~km}$; K). The position of the lidar site at Esrange is marked (black dot in the horizontal and thick green line in the vertical section). Numerical results are from the coarse grid domain of the mesoscale model $(\Delta x=27 \mathrm{~km})$. 
of $\Delta z \approx 230 \mathrm{~m}$. More important for a correct modeling of the vertical propagation of mountain waves into the stratosphere, however, is the modified radiative top boundary condition of Zängl (2002) which is applied in the current MM5 version. This boundary condition reduces the reflection at the model top significantly (Dörnbrack et al., 2002). Radiative and moist processes are switched off since the prime concern lies in the dynamics of mountain waves at upper levels. The initial conditions (15 January 1997, 12:00 UT) and boundary values of the model integration were prescribed by 6-hourly operational analyses of the ECMWF model with a horizontal resolution of $0.5^{\circ}$ in latitude and longitude and 15 pressure levels between the surface and the 10-hPa pressure level.

Figure 2 illustrates the simulated stratospheric temperature fields of the innermost model domain. Northern Scandinavia was located entirely inside the polar vortex on 16 January 1997. Inside the vortex the stratospheric temperature field at the isentropic surface $\Theta=550 \mathrm{~K}$ is rather uniform with $T \approx 192 \mathrm{~K}$ (over the Norwegian Sea in the horizontal sections of Fig. 2). Vertically propagating mountain waves generate elongated stratospheric temperature anomalies parallel to the mountain ridge. As will be discussed later, hydrostatic gravity waves in the non-rotating regime with horizontal wavelengths $\leq 100 \mathrm{~km}$ lead to vertical displacements of isentropes directly above the mountain ridge (compare the vertical sections in Fig. 2) whereas longer hydrostatic gravity waves in the rotating regime propagate also leeward (we use the terminology of Gill, 1982). At $\Theta=550 \mathrm{~K}$ the local temperature deviates from the average temperature inside the polar vortex by up to $12 \mathrm{~K}$. There are two dominating stratospheric temperature anomalies. At 00:00 UT, the horizontal distance between the westerly and the easterly one is about $150 \mathrm{~km}$ and increases to more than $400 \mathrm{~km}$ in the afternoon of 16 January 1997 (not within the display range of Fig. 2). Furthermore, the series of horizontal sections indicates an apparent downstream advection of the westerly cold anomaly towards the east. However, inspection of the vertical sections reveals that the horizontal wavelength of the westerly temperature anomaly increases from less than $50 \mathrm{~km}$ at 00:00 UT to about $200 \mathrm{~km}$ at 16:00 UT. Consequently, also its position relative to the mountain range shifts leeward. This is due to the excitation of hydrostatic gravity waves in the rotating regime by the long-lasting flow past the Scandinavian mountain ridge (e.g. Dörnbrack et al., 1999, 2002). These inertia-gravity waves have a non-vanishing horizontal component of the group velocity, therefore they are able to produce stratospheric temperature anomalies in the lee of the mountain ridge. Their smaller vertical group velocity compared to non-rotating hydrostatic waves lead to about 5 to 10 times larger propagation times to stratospheric levels and to an increasing distance between the westerly and easterly temperature minima during the day.

The coldest region inside the stratospheric temperature anomaly, however, propagates northward and is related to the position of the jetstream underneath. Figure 3 depicts the tropospheric meteorological evolution above the Scandinavian mountain range on 16 January 1997 . The prominent features are the northward-tilted tropopause (the white band in the vertical sections corresponding to a potential vorticity (PV) value of 2 PVU) and the tropopause fold associated with a strong jetstream. The difference between the tropopause heights on the cyclonic and the anticyclonic shear side of the jet is about $6 \mathrm{~km}$. The jetstream attains a maximum velocity of $\sim 60 \mathrm{~ms}^{-1}$ in its core. In the course of time the tropopause fold and jetstream advance northward (see the horizontal sections of PV and wind on the 308-K isentropic surface). Nearsurface winds upstream of Scandinavia are nearly perpendicular to the main mountain ridge. They peak at maximum values of $\sim 20 \mathrm{~ms}^{-1}$ at $850 \mathrm{hPa}$ between 00:00 UT and 12:00 UT and decrease afterwards significantly to values below $5 \mathrm{~ms}^{-1}$ (not shown). Hours later this weakening of the near-surfaces winds causes the wave activity in the stratosphere to decrease and eventually cease (after $\sim 18: 00$ UT, see Fig. 4).

The key to understanding the lidar observations at Esrange and the associated stratospheric temperature structure lies in the position of the jetstream relative to the lidar site. The large vertical shear of the zonal wind $\mathcal{U}$ in the troposphere $\partial \mathcal{U} / \partial z=60 \mathrm{~ms}^{-1} / 8000 \mathrm{~m}=7.5 \times 10^{-3} \mathrm{~s}^{-1}$ generates a Froude number profile $\mathcal{F}(z)=\mathcal{N} h / \mathcal{U}$ falling with altitude, where $\mathcal{N}$ is the buoyancy frequency $\left(\sim 0.01 \mathrm{~s}^{-1}\right)$ and $h \approx 1500 \mathrm{~m}$ is the height of the Scandinavian mountain ridge. In such regions, vertical gravity wave propagation is significantly facilitated. As a consequence, the strongest stratospheric cooling due to mountain waves is locked with the position of the jetstream advancing northward (see the stratospheric temperature anomaly in the vertical section of Fig. 3). The minimum temperature drops from $186 \mathrm{~K}$ (00:00 UT) to less than $182 \mathrm{~K}$ (16:00 UT) in the mountain wave-induced stratospheric temperature anomaly. In summary, the enhanced wave activity above the jetstream leads to an extra cold region in an altitude range between 22 and $26 \mathrm{~km}$ which proceeds northward while the longer horizontal mountain waves result in an eastward drift of the temperature anomaly.

\section{PSC macrophysical properties}

In the following we show that the use of mesoscale atmospheric modeling allows us to identify our measurements as those of a regional-scale quasi-stationary PSC system changing its position relative to Esrange. This mountain waveinduced PSC system enters the lidar field of view trailing edge first. First NAT particles and then more and more LTA droplets are detected as the outflow from a westerly waveinduced ice PSC which is subsequently monitored. Such PSC systems are well known from observations with airborne lidars (e.g. Wirth et al., 1999; Dörnbrack et al., 2002), but have not been measured with ground-based lidars before.

The stratospheric temperature field downstream the Scandinavian mountains can be best described as a series of 

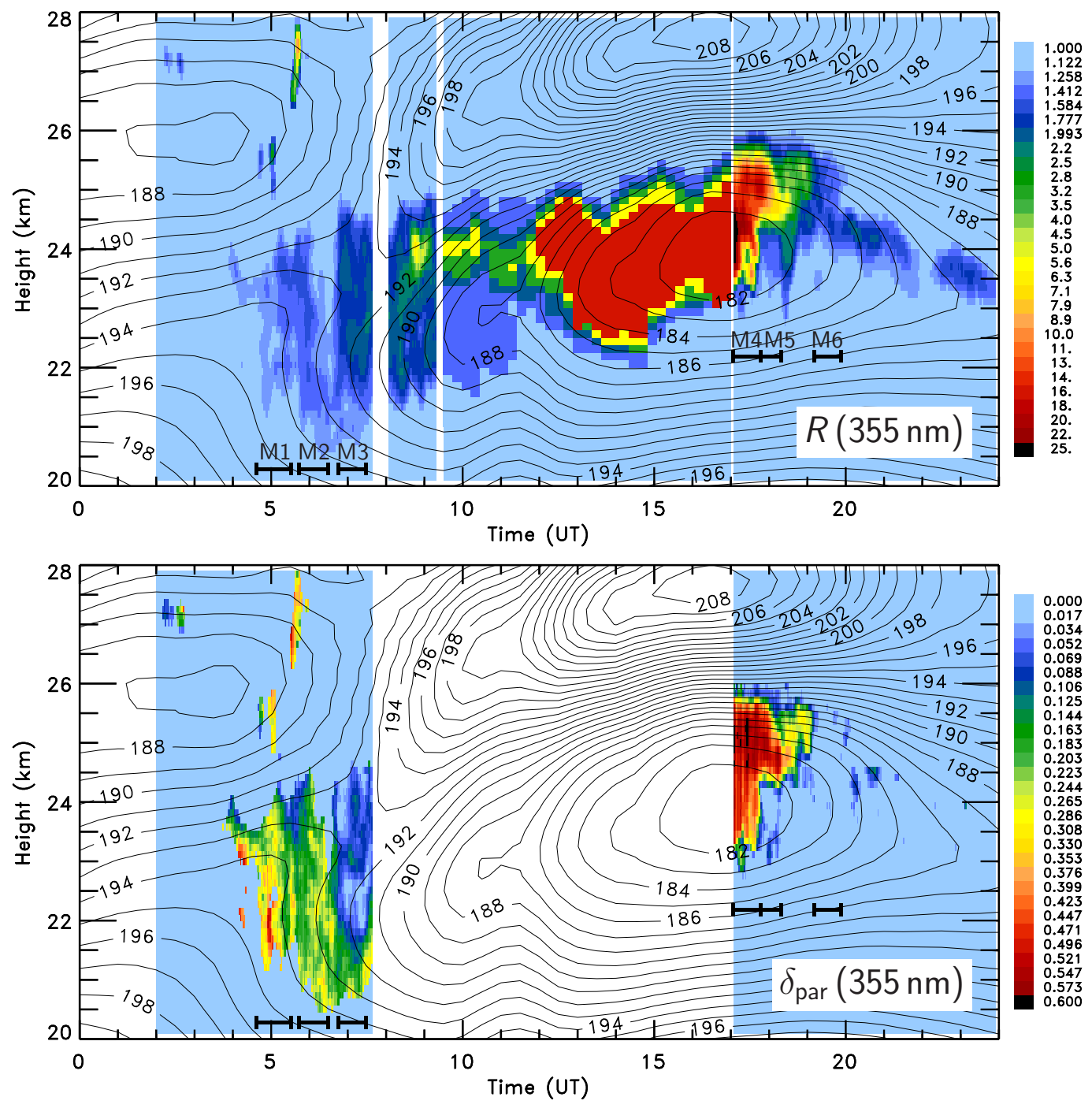

Fig. 4. Temporal evolution of 355-nm backscatter ratio $R$ and of 355-nm particle depolarization ratio $\delta_{\text {par }}$ on 16 January 1997 over Esrange. Superimposed is the temperature (solid lines; $\mathrm{K}$ ) from the innermost domain of the mesoscale numerical simulation $(\Delta x=3 \mathrm{~km})$. Measurement intervals M1-M6 are marked. Backscatter-ratio data between 09:30 and 17:00 UT were taken from Baumgarten (1997). The original measurements at a wavelength of $532 \mathrm{~nm}$ (parallel polarization only) were converted to $355-\mathrm{nm} R$ values assuming wavelength-independent particle scattering. In view of the coarse gradation of the 532-nm data available, no effort was made to account for their polarization sensitivity.

temperature minima parallel to the ridge (Fig. 2). As the result of the combined synoptic and mesoscale dynamics, the temperature profile above Esrange changes substantially over time (Fig. 4). In the morning of 16 January 1997, stratospheric conditions at the lidar site are governed by the easterly temperature anomaly leading to temperatures warmer and colder than $192 \mathrm{~K}$ at heights below and above $\sim 23 \mathrm{~km}$, respectively. Due to the long-lasting flow past the mountain ridge and the associated dilatation of the horizontal wavelength this pattern reverses gradually. At $\sim 07: 00 \mathrm{UT}$, the stratosphere between 21 and $27 \mathrm{~km}$ is nearly isothermal. Later on, the intensifying westerly temperature anomaly dominates the temperature field over Esrange with temperatures colder below, and warmer above, the sloping 192-K isotherm.

The main PSC event is related to the development of the westerly stratospheric temperature anomaly. It starts around 04:00 UT when first particle backscattering is measured at $23.5-24 \mathrm{~km}$. Over the next two hours the PSC cloud base lowers to minimum heights around $20.5 \mathrm{~km}$. This correlates with a decrease in temperature at altitudes $<23 \mathrm{~km}$. Afterwards, PSC base and top move steadily upwards by $\sim 170 \mathrm{~m} / \mathrm{h}$ until 19:30 UT with the geometrical thickness of the PSC remaining nearly constant at $\sim 3 \mathrm{~km}$. The simulated 
stratospheric temperature anomaly also shows this upward propagation.

PSC optical data before 07:40 UT reveal an increase of $R$ and a reduction of $\delta_{\text {par }}$ with decreasing temperature. The change is particularly pronounced at sunrise around 06:40 UT. This transition in PSC optical signature, which is discussed in greater detail in Sect. 5.1, suggests that scattering by LTA droplets increasingly dominates scattering by solid particles, most likely consisting of NAT (the edge of the PSC follows quite well the NAT equilibrium temperature $T_{\mathrm{NAT}}$ ).

After sunrise and until $\sim$ 17:00 UT, $R$ values continue to increase while the ambient air masses are cooling. Backscatter spikes at $24 \mathrm{~km}$ between 09:00 UT and 11:30 UT are probably caused by PSC patches consisting predominantly of ice particles (type-II PSC) rather than by LTA droplets (typeIb PSC) or crystalline NAT particles (type-Ia PSC) because $R$ values clearly exceed those expected for type-I PSCs. Between 13:00 UT and 18:00 UT the cold core of the westerly temperature anomaly resides directly above Esrange. The mesoscale simulation indicates minimum temperatures of $181 \mathrm{~K}$ at $24 \mathrm{~km}$ which is about $3 \mathrm{~K}$ below the frost point. Therefore one can conclude that the extreme backscatter ratios ( $>25$ at $355 \mathrm{~nm},>150$ at $532 \mathrm{~nm}$ ) and particle depolarization ratios $(>0.5)$ measured by the two lidars are the optical signature of a PSC II where the ice particles nucleated not far upstream of the observation site.

After 18:00 UT wave activity weakens leading to an upstream shift of the attenuating temperature minimum. The Esrange lidars monitor the outflow of the westerly temperature anomaly again. Around 19:00 UT the PSC collapses to a $0.5-\mathrm{km}$ wide layer. Associated with the change in geometrical properties is a drastic transition in PSC backscatter and particle depolarization ratios. The slowly subsiding thin PSC clearly exhibits the optical characteristics of a PSC Ib, except for short-lived patches around 20:00 UT with elevated $\delta_{\text {par. }}$. Apparently, the windward temperature minimum shallowed to such an extent that nucleation of solid particles is significantly reduced. Wave-processing foremost results in growth and evaporation of the liquid aerosol. This cloud could have extended to the western side of the Scandinavian mountain ridge where a PSC with similar properties was observed at the same time (Fricke et al., 1999). The transition from PSC II to PSC Ib as observed between 17:00 UT and 20:00 UT over Esrange will be discussed in more detail in Sect. 5.2.

\section{PSC microphysical properties}

In this Section we present the results of our microphysical studies that helped us derive the general interpretation of our lidar measurements on 16 January 1997 given before. We focus on the two major events that were captured with the GKSS Raman lidar, specifically, these are the transitions in the PSC optical characteristics from PSC Ia (with enhanced $R$ ) to PSC Ib (04:00-09:00 UT), and from PSC II to PSC Ib (17:00-20:00 UT).

\subsection{PSC observations in the morning of 16 January 1997}

Figure 5 displays the evolution of the PSC backscatter-ratio and depolarization-ratio profiles in the morning of 16 January 1997. To increase the precision of the $\bar{S}_{\text {par }}$ determination, lidar data are summed over three consecutive measurement intervals M1-M3 with relatively little variation in PSC optical and geometrical properties (cf. Fig. 4). Generally, $\delta_{\text {par }}$ and $\bar{S}_{\text {par }}$ decrease, and $R$ increases, with time although some exceptions exists. For example, cloud-base $\delta_{\text {par values mea- }}$ sured during interval M3 are similar to those observed during interval M2. Apparently, LTA droplets that depress $\delta_{\text {par }}$ at the PSC altitudes above are smaller in number, small in size, or completely absent here. Interestingly, $\bar{S}_{\text {par }}$ values of intervals M2 and M3 are comparable despite the significant change in the fractional contributions of crystalline and liquid particles to PSC light scattering (see Fig. 6). As we will discuss later, decomposition of the PSC optical signature into particle-type specific optical properties as well as microphysical considerations suggest that the solid and liquid particles indeed have similar lidar ratios that change little over time.

To facilitate interpretation of the lidar measurements, backward trajectories based on mesoscale simulation fields were calculated. Air parcel temperature histories are presented in Fig. 5 for selected PSC heights. The last two hours prior to the lidar observations are shown. The mountain wave induced several cycles of cooling and heating of which, in the case of the main PSC layer between 20 and $25 \mathrm{~km}$, the most pronounced occurred $30 \mathrm{~min}$ before the observations. In this temperature anomaly of rather short duration, the air masses are cooled by several degrees Kelvin to minimum temperatures with high cooling rates (particularly during measurements M2 and M3 at heights $<23 \mathrm{~km}$ ), but reach only in one case $(22.5 \mathrm{~km}$, measurement M3) temperatures $3-4 \mathrm{~K}$ below the frost point (assuming 5 ppmv $\mathrm{H}_{2} \mathrm{O}$ ) which is generally regarded as the threshold temperature range for ice-particle nucleation (Tabazadeh et al., 1997; Carslaw et al., 1998). However, considering the accuracy of the mesoscale numerical simulations, and in view of observational evidence we consider it very likely that mountain wave temperatures actually fell below this nucleation threshold in all cases, and that solid particles subsequently formed. Previous studies show that the discrepancies between simulated and measured temperatures can be several degrees Kelvin, with the mesoscale model temperatures consistently being warmer (Larsen et al., 2002; Fueglistaler et al., 2003). In our case, a temperature correction of -1 to $-3 \mathrm{~K}$ (depending on height) would be required to trigger ice nucleation both in the morning (Fig. 5) and the afternoon (Fig. 7) of 16 January (all other parameters unchanged), which is in the range of temperature corrections Larsen et al. (2002) had to apply to match 

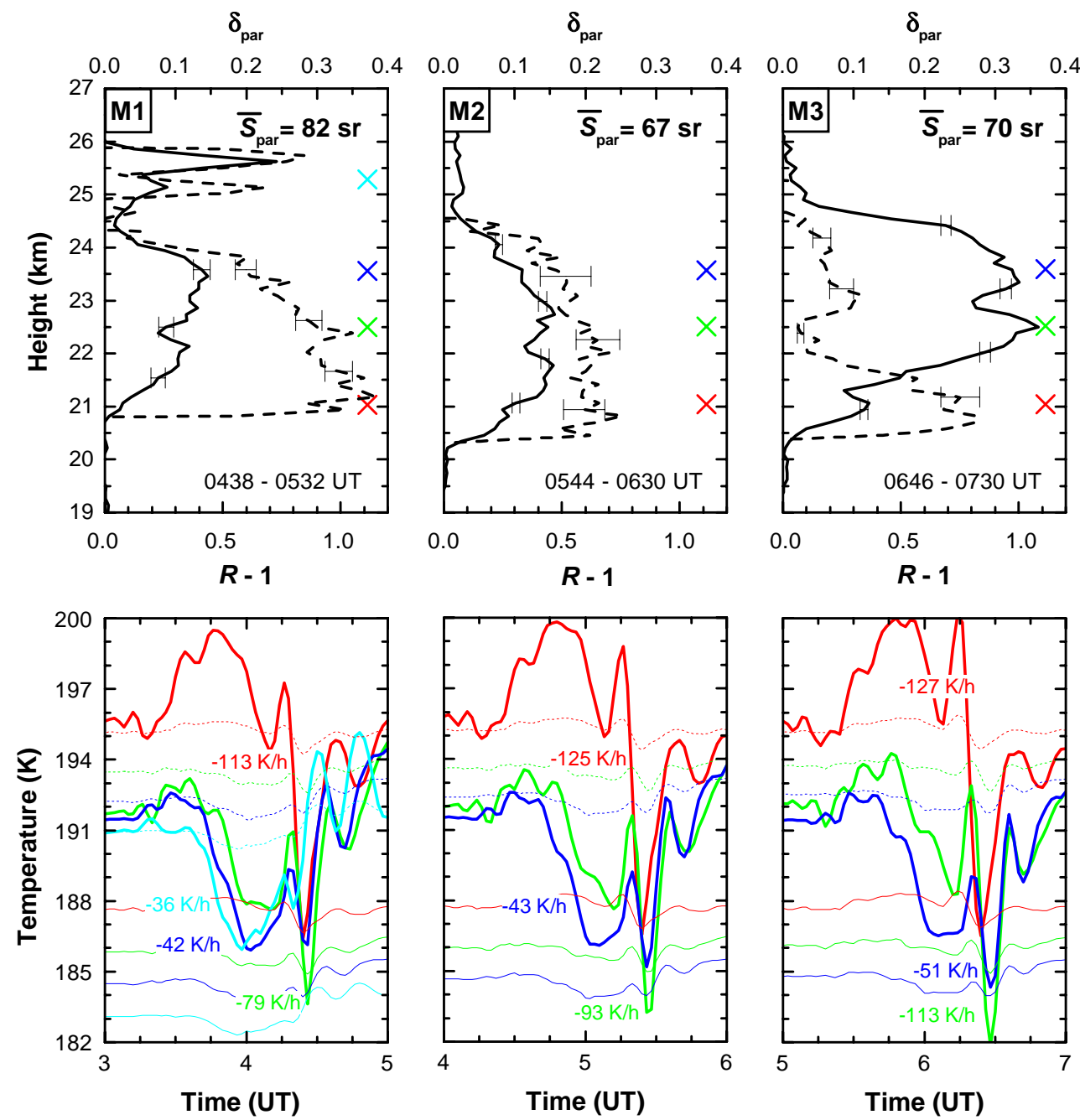

Fig. 5. Backscatter ratio $R$ (solid curves) and particle depolarization ratio $\delta_{\text {par }}$ (dashed curves) of the mountain wave PSC as observed with the GKSS Raman lidar in the morning of 16 January 1997 (top panels). Mean lidar ratio $\bar{S}_{\text {par }}$ is indicated. Lidar data were integrated over measurement intervals with similar PSC optical and geometrical properties (M1-M3). The vertical resolution is $120 \mathrm{~m}$, the measurement wavelength is $355 \mathrm{~nm}$. Error bars indicate the standard deviation due to signal noise. Air parcel temperature histories derived from mesoscale numerical simulations (bottom panels). Starting at 05:00, 06:00, and 07:00 UT (about the center times of M1-M3) and at various heights (colored symbols, top panels), the trajectories are calculated backward in time. Ambient temperatures (solid curves), frost point temperatures (thin solid curves) and NAT equilibrium temperatures (thin dashed curves; calculated according to Hanson and Mauersberger (1988)) are shown. A water vapor mixing ratio of $5 \mathrm{ppmv}$ and $\mathrm{HNO}_{3}$ mixing ratio of $14 \mathrm{ppbv}$ are assumed. Maximum cooling rates are indicated. Temperatures and cooling rate are shown in the color of the corresponding start height.

microphysical simulations and observations. The assessment that model temperatures may be too warm is corroborated by the experimental data. First, large amounts of LTA are observed above $22 \mathrm{~km}$ in measurement interval M3. Our model simulations yield temperatures within $1 \mathrm{~K}$ below $T_{\mathrm{NAT}}$ in the LTA layer, while the theoretical work of Carslaw et al. (1994) on equilibrium growth of liquid aerosol show that LTA volume does not increase significantly unless temperatures fall several degrees Kelvin below $T_{\mathrm{NAT}}$. Second, in the afternoon lidars upwind Esrange on the weather side of the Scandinavian mountains detect a PSC type $\mathrm{Ib}$ with a weak lidar backscatter only while a PSC II is monitored above Es- range (Fricke et al., 1999), which implies that the ice particles formed on their way between both sites.

As discussed previously, the transition in PSC optical properties observed in measurements M1-M3 is the result of changes in the size distributions of the coexisting solid and liquid particles. The main cause is the decrease in temperature in general, and above Esrange in particular, with time, allowing the LTA droplets to grow to larger volume in the mountain wave, and to maintain larger sizes during their subsequent advection to the lidar site (Fig. 5). The different trends in the evolution of the two particle types are visible in the ratios of polarized particle backscatter coefficients 

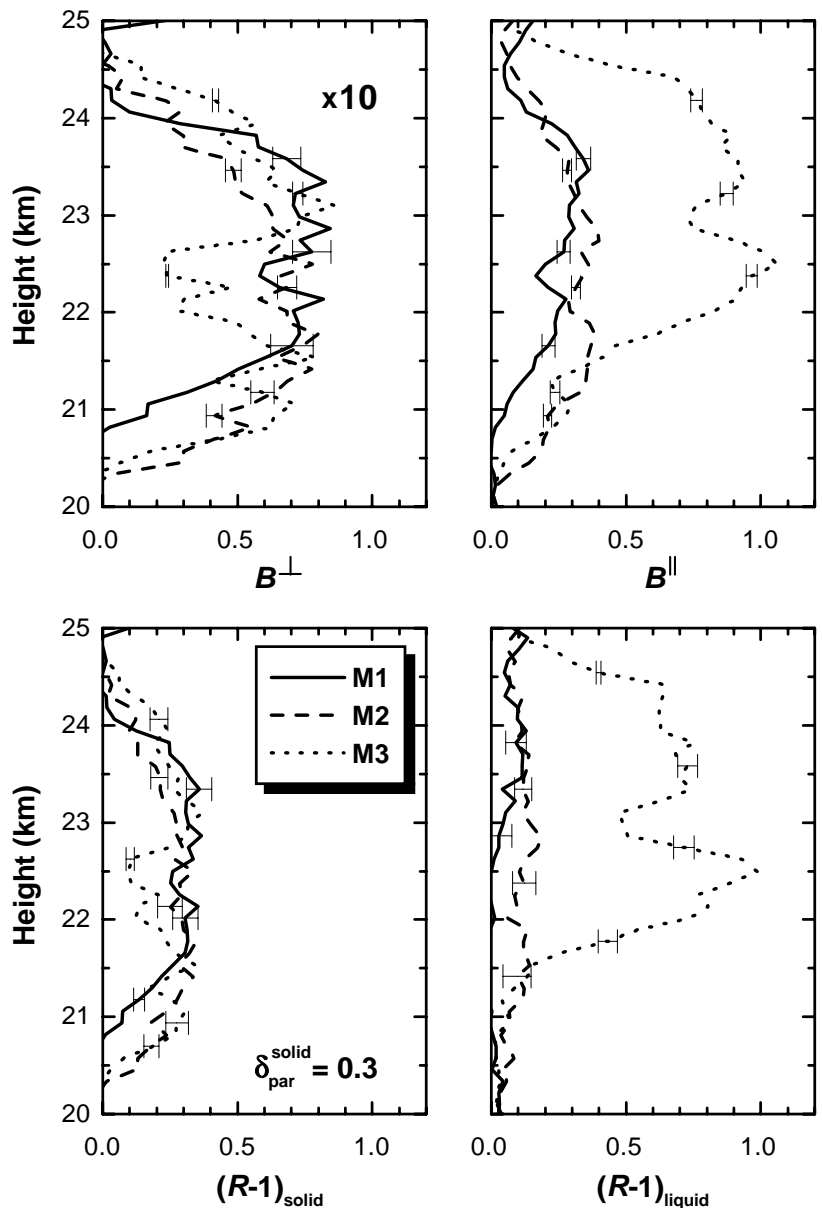

Fig. 6. Coexistence of solid and liquid PSC particles observed in the morning of 16 January 1997. Ratio of perpendicular-polarized particle backscatter coefficient to molecular backscatter coefficient $\left(B^{\perp}\right)$, ratio of parallel-polarized particle backscatter coefficient to molecular backscatter coefficient $\left(B^{\|}\right)$, and scattering contributions of solid $\left[(R-1)_{\text {solid }}\right]$ and liquid $\left[(R-1)_{\text {liquid }}\right]$ particles to the PSC backscatter ratio for measurement intervals M1-M3. $(R-1)_{\text {solid }}$ and $(R-1)_{\text {liquid }}$ are retrieved under the assumption that solid particles at all PSC heights have depolarization ratios similar to those measured below $22.5 \mathrm{~km}$ during time period M1 $\left(\delta_{\text {par }}^{\text {solid }} \approx 0.3\right)$. Error bars reflect uncertainties in $\delta_{\text {par }}^{\text {solid }}$ of \pm 0.05 .

to molecular backscatter coefficient (Fig. 6). $\quad B^{\|}$indicates the significant temperature-related increase in droplet volume while, in contrast, $B^{\perp}$ exhibits little variability. From the spatial and temporal homogeneity of $B^{\perp}$ the important conclusion can be drawn that the optical and microphysical properties of the crystalline particles are similar throughout the vertical extent of the PSC and remain unchanged during measurement intervals M1-M3. Consequently, the most accurate measurement of the depolarization ratio of scattering by these solid particles, $\delta_{\mathrm{par}}^{\text {solid }}$, is obtained at heights and times where temperatures are too warm for liquid particles to exist in significant amounts. This condition should be approximately met in measurement $\mathrm{M} 1$, and we obtain $\delta_{\mathrm{par}}^{\text {solid }}=0.3 \pm 0.05$. With this estimate we are able to calculate the contributions of solid and liquid particles to the PSC backscatter ratio. Using the defining equations of $B^{\perp}, B^{\|}$, and $\delta_{\text {par }}^{\text {solid }}\left(\delta_{\text {par }}^{\text {liquid }}=0\right)$, we obtain

$(R-1)_{\mathrm{solid}}=B^{\perp}\left(1+1 / \delta_{\mathrm{par}}^{\mathrm{solid}}\right)$,

$(R-1)_{\text {liquid }}=B^{\|}-B^{\perp} / \delta_{\mathrm{par}}^{\text {solid }}$,

with $R-1=(R-1)_{\text {solid }}+(R-1)_{\text {liquid. }}$ The results of the computations are shown in Fig. 6. Solid-particle scattering dominates measurements $\mathrm{M} 1$ and $\mathrm{M} 2$; the low $(R-1)_{\text {liquid values }}$ may either indicate scattering by few or small coexisting LTA droplets, or be the residual of our computations if $\delta_{\mathrm{par}}^{\text {solid }}$ was overestimated. In contrast, $(R-1)_{\text {liquid }} \gg(R-1)_{\text {solid }}$ is found in measurement M3 for heights $>22 \mathrm{~km}$.

We mentioned before that $\bar{S}_{\text {par }}$ values of measurements M2 and M3 are similar. Since our trend analysis of Fig. 6 suggests that the optical properties of the solid particles remain the same, this must also be the case for the LTA droplets. For this reason, we will assume $S_{\text {par }}=(70 \pm 14) \mathrm{sr}$ (20\% systematic error, see Section 2) for both crystalline PSC particles $\left(\delta_{\mathrm{par}}^{\text {solid }}=0.25-0.35\right.$, measurements M1-M3) and liquid PSC particles $\left(\delta_{\text {par }}^{\text {liquid }}=0\right.$, measurement M3 $)$ in our retrieval of microphysical properties. The elevated $\bar{S}_{\text {par }}$ value measured during time period M1 is not considered representative of the solid particles, since the appearance of an isolated and short-lived PSC patch around $25.5 \mathrm{~km}$ (Figs. 4 and 5) might affect the accuracy of the $\bar{S}_{\text {par }}$ measurement for the main PSC layer. Furthermore, we will assume that the solid particles consisted of NAT as was observed in situ by Voigt et al. (2000) under conditions similar to ours (particles sampled about $2 \mathrm{~h}$ downwind a mountain wave-induced PSC II).

\subsection{PSC observations in the afternoon of 16 January 1997}

Figure 7 shows our PSC measurements during and shortly after the core of the mountain wave-induced temperature anomaly resided over Esrange. PSC optical signatures are remarkably different from those observed earlier (Fig. 5). During measurements M4 and M5, $R$ and $\delta_{\text {par }}$ reach maximum values of, respectively, $10-20$ and $0.5-0.65$, while $\bar{S}_{\text {par }}$ decreases to 20-35 sr. These optical characteristics, which are similar to those of cirrus clouds (Reichardt et al., 2002a), leave no doubt that the PSC consisted of large water-ice particles (PSC type II). The temperature histories confirm cooling of the advected air masses of up to $15 \mathrm{~K}$ with minimum temperatures being reached only minutes before lidar detection at Esrange. Thus the lidars were monitoring newly nucleated ice particles during time periods M4 and M5 in the main PSC layer. Below $24.2 \mathrm{~km}$ during measurement M5, however, the meteorological conditions must have been different since $R$ and $\delta_{\text {par }}$ are significantly smaller. The $\delta_{\text {par }}$ values of 0.05 0.1 could be explained by scattering by predominant LTA droplets in coexistence with a small number of crystalline 

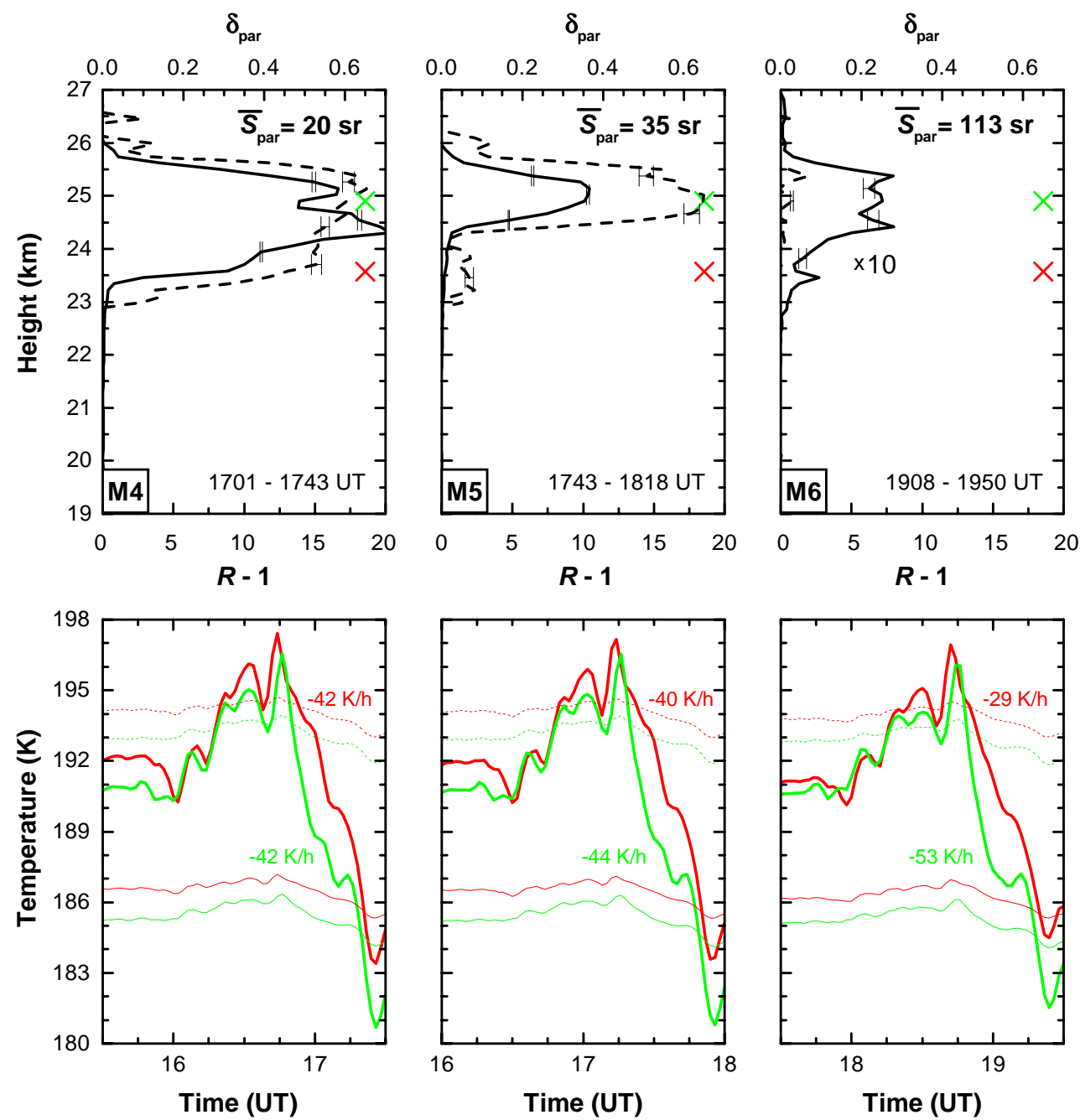

Fig. 7. Same as in Fig. 5, but for the afternoon of 16 January 1997 (measurements M4-M6). Backscatter ratio of measurement M6 was multiplied by a factor of ten.

particles. The same may be the case for the main PSC layer around $25 \mathrm{~km}$ in measurement M6, but the precision of the experimental data is not sufficient to test this hypothesis.

Since in measurements M4-M6 scattering by either solid or liquid particles dominates, analysis of $B^{\perp}$ and $B^{\|}$does not yield any additional information and is, therefore, not shown. Finally, we would like to point out that in all the measurements M1-M6 cooling was rapid $(\gg 10 \mathrm{~K} / \mathrm{h})$. According to the study of Luo et al. (2003) we can thus expect the ice particle number density to be limited by the number density of the background aerosol only. Furthermore, NAT particles should be significant in number if NAT formed via deposition nucleation on ice particles.

\subsection{Microphysical retrieval}

In the following, PSC microphysical properties retrieved from the lidar measurements are discussed. Solid particles are assumed to consist of NAT, or ice. For NAT a refractive index of 1.53 as observed by Deshler et al. (2000) is chosen, for ice the data of Warren (1984) are used (refractive index of 1.32 at $355 \mathrm{~nm}$ ). Phase matrices of hexagons and irregular particles are calculated with the finite-difference timedomain method described by Yang et al. (2000). Scattering properties of spheroids with aspect ratios (defined as the ratio of length to diameter of the particle) smaller or larger than one are calculated according to the T-matrix technique.

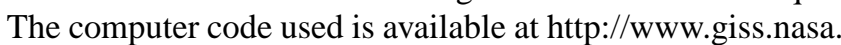
gov $/ \sim$ crmim/t_matrix.html (Mishchenko, 1991). Mie theory is applied to determine the phase functions of spheres (van de Hulst, 1981). For a discussion of the optical constants selected, and for more details about the computations see Reichardt et al. (2002c).

It is assumed that the size distribution of the optically relevant PSC particles is narrow. In the case of mountain wave PSCs this approximation is justified as in situ measurements 
(Voigt et al., 2000), microphysical modeling (Tsias et al., 1999; Larsen et al., 2002), and size-spectrum-resolved retrievals from lidar data (Tsias et al., 1999; Wirth et al., 1999; Toon et al., 2000; Hu et al., 2002) confirm. The analysis first focuses on solid particles, specifically those observed during measurement intervals M1-M3, M4 and M5.

\subsubsection{Solid particles}

Estimates of particle shapes, sizes, and number concentrations are obtained by comparing measurements and theoretical optical data. For the first time lidar ratio is used in the retrieval next to particle depolarization ratio. $S_{\text {par }}$ and $\delta_{\text {par }}$ are two optical properties that ideally complement one another because they contain different information about the scattering matrix of the PSC particle ensemble. Both are independent of the particle number concentration and thus can be directly used to infer particle microphysical characteristics.

Different principal particle shapes are investigated. Studies by Liu and Mishchenko (2001) and Reichardt et al. (2002c) demonstrate that retrieval results depend strongly on the assumed shapes of the particles, but to our knowledge PSC observations with lidar were analyzed by use of a spheroidal particle model only (Carslaw et al., 1998; Tsias et al., 1999; Wirth et al., 1999; Flentje et al., 2002; Hu et al., 2002; Fueglistaler et al., 2003). In this study we compare the lidar data to the optical properties of spheroids, hexagons, and, for the first time, particles without any symmetry (irregular particles).

Figure 8 compares measured and theoretical optical properties of solid PSC particles. Theoretical lidar ratio and particle depolarization ratio are plotted versus the maximum dimension of the particles. Measurements are visualized with solid horizontal lines. Lengths and positions indicate particle size ranges with best-possible agreement between observations and theoretical data. The size ranges are relatively well defined in most cases, despite the fact that only two optical properties are available to constrain the retrieval. The reason for the stability of the solutions is the opposite dependence of $\delta_{\text {par }}$ and $S_{\text {par }}$ on particle maximum dimension. Only if the particles are much larger than the observation wavelength, as it is the case in measurements M4 and possibly in M5, $S_{\mathrm{par}}$ and $\delta_{\text {par }}$ are not sensitive to changes in particle size any more, and the retrieval results become unstable.

For the solid particles observed during measurement intervals M1-M3, good agreement between measured and theoretical optical data for a broad range of sizes is found for irregular NAT and hexagonal ice particles. Nevertheless we can exclude the ice particles from our analysis if we take into account that in the morning of 16 January ambient temperatures were significantly warmer than $T_{\text {ice }}$, and that a well developed hexagonal symmetry is rather unlikely for small ice particles with $0.8-1.4 \mu \mathrm{m}$ maximum dimension anyway. Examining the optical data of irregular NAT particles closer, we find that the particles most likely had maximum dimensions between 0.7 and $0.9 \mu \mathrm{m}$ and aspect ratios between 0.75 and 1.25 or sizes of about $1.1 \mu \mathrm{m}$ with either small $(0.5)$ or large (1.5) aspect ratios.

From $(R-1)_{\text {solid }} \approx 0.3$ it then follows that the particle number density was $n_{\mathrm{NAT}}=8-12 \mathrm{~cm}^{-3}$, and that condensation of gas-phase $\mathrm{HNO}_{3}$ was equivalent to $4.5-7.6 \mathrm{ppbv}$ (generally, retrieval results are such that small maximum dimensions correspond to high number densities and small amounts of condensed $\mathrm{HNO}_{3}$, and vice versa). A summary of all measured optical and retrieved microphysical properties is given in Table 1.

Our retrieval results are consistent with those of previous studies of NAT PSCs with high $n_{\text {NAT }}\left(\gg 1 \mathrm{~cm}^{-3}\right)$ downwind mountain waves with rapid cooling $(\gg 10 \mathrm{~K} / \mathrm{h})$ (Tsias et al., 1999; Wirth et al., 1999; Toon et al., 2000). Furthermore, our data are in good agreement with the theoretical relationship between $n_{\mathrm{NAT}}$ and cooling rate as derived by Luo et al. (2003) assuming NAT forming via deposition nucleation on ice particles, and thus can be considered as additional observational evidence of this hypothesis.

M4 and M5 observations are compared to theoretical optical data of ice crystals only, since the elevated backscatter ratios are too high for PSCs consisting of NAT particles, even for those generated by mountain waves (Tsias et al., 1999; Reichardt et al., 2000b). M4 depolarization ratios agree well with $\delta_{\text {par }}$ values of irregular ice particles $>1.9 \mu \mathrm{m}$, but measured lidar ratios are smaller than the theoretical data, even for a particle maximum dimension of $2.7 \mu \mathrm{m}$. If a hexagonal particle shape is assumed, M4 measurements do not fit the computational results for particle sizes $<2.7 \mu \mathrm{m}$, but are close to the theoretical values obtained in the geometricaloptics approximation for columnar hexagons with aspect ratios between 1 and 2.5. This similarity implies that the particles observed during measurement interval M4 were large, probably $\gg 3 \mu \mathrm{m}$.

In the case of measurement M5, observation and theory are in excellent agreement for isometric and slightly oblate irregular ice particles (aspect ratios of 0.75 and 1) with sizes $>1.9 \mu \mathrm{m}$. Theoretical $S_{\text {par }}$ values of hexagons indicate similar particle maximum dimensions, yet measured and calculated $\delta_{\text {par }}$ disagree. Again, the upper boundary of the particle size range cannot be retrieved because our observation at $355 \mathrm{~nm}$ is lacking sensitivity to size for large particles. For a more accurate size estimate, observations at longer wavelengths would be needed. The lower limit of the particle maximum dimension $(>1.9 \mu \mathrm{m})$ confines the particle number density to $n_{\text {ice }}<27 \mathrm{~cm}^{-3}$. This upper boundary is probably too high since $n_{\text {ice }}$ should not be larger than the number concentration of the background aerosol (Luo et al., 2003), but maximum $n_{\mathrm{CN}}$ values measured in (mountain wave) PSCs are, to our knowledge, about $20 \mathrm{~cm}^{-3}$ (Larsen et al., 2002).

Assuming spheroidal particle shapes, we retrieve a mixture of slightly oblate and prolate particles (aspect ratios of 

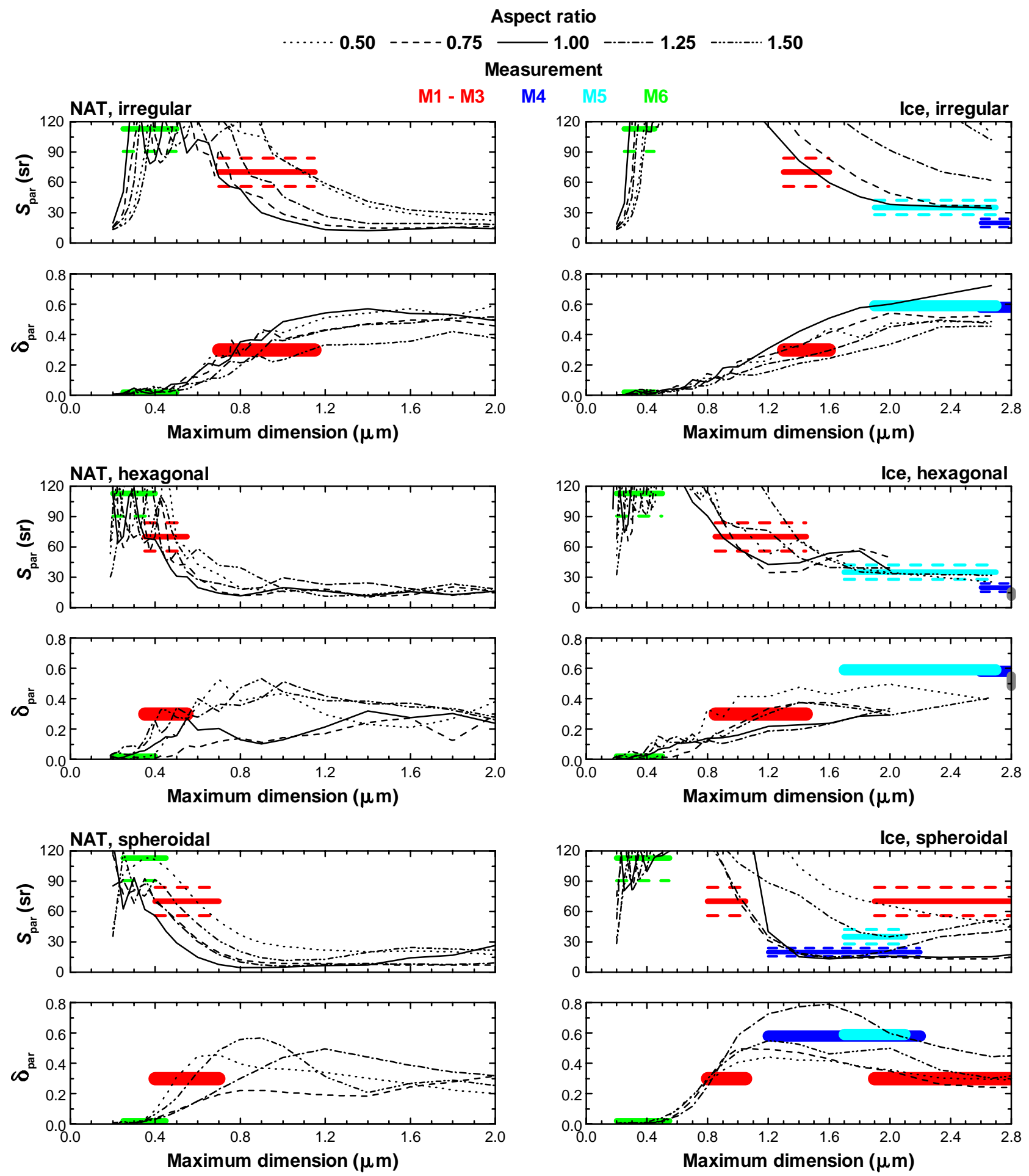

Fig. 8. Retrieval of microphysical properties of solid PSC particles from measurements M1-M6. Measured data are visualized with solid horizontal lines, line lengths and positions indicate particle size ranges that show best agreement between observations and theoretical data. Line thickness of measured $\delta_{\text {par }}$ indicates variability of the PSC profile, dashed horizontal lines show estimated systematic errors of

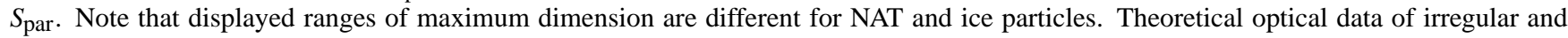
hexagonal particles, spheroids (aspect ratios $\neq 1$ ), and spheres were obtained with, respectively, finite-difference time-domain, T-matrix, and Mie computations. Results of geometrical-optics calculations for hexagonal ice columns are also shown (gray marks, center, right; aspect ratios between 1 and 2.5, slightly distorted shape, see Hess et al., 1998; Reichardt et al., 2002b). The wavelength is $355 \mathrm{~nm}$. 
Table 1. PSC Optical $(355 \mathrm{~nm})$ and Retrieved Microphysical Properties. COMP, RI, AR, and MD Denote Composition, Refractive Index, Aspect Ratio, and Maximum Dimension, respectively.

\begin{tabular}{ccccccccccc}
\hline Measurement & $\delta_{\text {par }}$ & $\begin{array}{c}S_{\text {par }} \\
\text { sr }\end{array}$ & $R-1$ & COMP & RI & Shape & AR & $\begin{array}{c}\mathrm{MD} \\
\mu \mathrm{m}\end{array}$ & $\begin{array}{c}\mathrm{n} \\
\mathrm{cm}^{-3}\end{array}$ & $\begin{array}{c}\mathrm{HNO}_{3} \text { cond. } \\
\text { ppbv }\end{array}$ \\
\hline M1-M3 & $0.25-0.35$ & $70 \pm 14$ & 0.3 & NAT & 1.53 & irregular & $0.75-1.25 ; 0.5,1.5$ & $0.7-0.9 ; 1.1$ & $8-12$ & $4.5-7.6$ \\
M3 & 0 & $70 \pm 14$ & 0.6 & LTA & 1.39 & spherical & 1 & $0.7-0.9$ & $7-11$ & $3.7-4.8$ \\
M4 & $0.52-0.64$ & $20 \pm 4$ & $15-20$ & ice & 1.32 & irr., hex. & & $>3$ & 0 \\
M5 & $0.55-0.65$ & $35 \pm 7$ & 10 & ice & 1.32 & irregular & $0.75-1$ & $>1.9$ & $<27$ & 0 \\
M6 & 0 & $113 \pm 22$ & 0.7 & LTA & 1.37 & spherical & 1 & $0.8-0.9$ & $9-10$ & $3.4-6.5$ \\
\hline
\end{tabular}

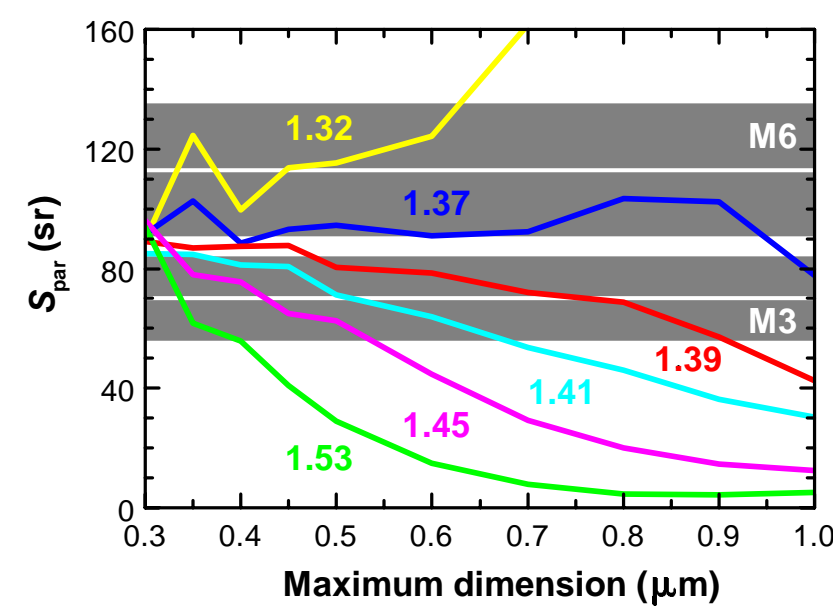

Fig. 9. Retrieval of microphysical properties of liquid PSC particles from measurements M3 and M6. Measured $S_{\text {par }}$ data are indicated with white horizontal lines, shaded areas visualize estimated systematic errors. Mie theory was applied to calculate the optical properties of LTA droplets, assuming different chemical compositions (refractive indices are indicated). Computational results obtained for pure water ice and NAT are shown for comparison (refractive index of 1.32 and 1.53 , respectively). The wavelength is $355 \mathrm{~nm}$.

0.75 and 1.25) for the PSC observed during measurement M4. In the case of observation M5, agreement between theoretical and observed data is confined to a very narrow range of size for particles with aspect ratio between 1.25 and 1.5. In contrast to the results obtained for irregularly shaped crystals and hexagons, the spheroidal particle model yields both lower and upper bounds of particle size for measurements M4 and M5, and the particles are considerably smaller. This example illustrates how the retrieval of microphysical properties from lidar data depends on the assumptions made about particle shape. Thus one has to be careful with microphysical data that were obtained using only one particular particle model.

Finally, we analyze measurement M6 because, in theory, the optical signature of this PSC $\left(\delta_{\mathrm{par}}<5 \%, S_{\mathrm{par}}=113 \mathrm{sr}\right)$ could stem from scattering by solid particles alone. Independently of particle composition and shape, observed and cal- culated optical properties agree well for particle maximum dimensions between 0.2 and $0.5 \mu \mathrm{m}$. However, to explain the backscatter ratio of 1.7 with these small particles, one would have to assume number concentrations that are not realistic $\left(n_{\text {ice }}>150 \mathrm{~cm}^{-3}, n_{\mathrm{NAT}}>65 \mathrm{~cm}^{-3}\right)$. Thus we conclude that during measurement interval M6 solid and liquid PSC particles coexisted, and that LTA droplets dominated light scattering.

\subsubsection{Liquid particles}

Figure 9 compares M3 and M6 lidar-ratio measurements of liquid PSC particles with 355-nm theoretical data. Different chemical compositions of the LTA droplets were assumed in the Mie computations. In the stratosphere, an increase in temperature is related to a decrease in the water contents of the ternary solution and, thus, to an increase in LTA refractive index. In the $\mathrm{UV}$ it varies between $1.37\left(88 \mathrm{wt} \% \mathrm{H}_{2} \mathrm{O}\right.$, $T \approx T_{\text {ice }}-4 \mathrm{~K}$ ) and $1.45\left(55 \mathrm{wt} \% \mathrm{H}_{2} \mathrm{O}, T \approx T_{\text {ice }}+3 \mathrm{~K}\right.$ ) (Luo et al., 1996; Krieger et al., 2000).

It is important to note that refractive indices between 1.39 and 1.53 correspond to diameters between 0.85 and $0.35 \mu \mathrm{m}$, respectively, for an assumed lidar ratio of $70 \mathrm{sr}$. Therefore it seems possible that the lidar ratio of a population of LTA droplets evaporating due to warming temperatures remains relatively unchanged, as we assumed to explain the almost

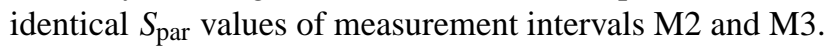

The optical data also show that the refractive index of the LTA droplets was smaller in measurement M6 than during the earlier observation $\mathrm{M} 3$, which is in accordance with the mesoscale numerical simulation of colder PSC temperatures for the afternoon. The relatively high backscatter ratios of $1.6-1.7$ in both cases require the droplets sizes to be large since otherwise droplet concentrations would be too high. Considering temperature and $R$ values, we infer an LTA refractive index of 1.39, droplet diameters of $0.7-0.9 \mu \mathrm{m}$, and particle concentrations of $7-11 \mathrm{~cm}^{-3}$ for measurement M3. These values correspond with condensation of $3.7-4.8 \mathrm{ppbv}$ $\mathrm{HNO}_{3}$ out of the gas phase.

Combining the results of our microphysical retrieval for LTA and NAT particles, we obtain a total particle number density of $15-23 \mathrm{~cm}^{-3}$. Given the high stratospheric cooling 
rates in the morning of 16 January 1997, it appears likely that about all of the supercooled droplets nucleated ice particles in the mountain wave upwind Esrange (Luo et al., 2003 ), which would mean that on $\sim 53 \%$ of these particles ice-mediated nucleation of NAT occurred. Wirth et al. (1999) report a similar fraction for a mountain wave PSC with comparable cooling rates. The total amount of condensed $\mathrm{HNO}_{3}$ sums up to 8.2 to $12.4 \mathrm{ppbv}$. This compares well with the microphysical model results obtained for the mountain wave PSC studied by Larsen et al. (2002). According to Larsen et al. (2002), depletion of the $\mathrm{HNO}_{3}$ gas reservoir can reach $100 \%$ (or $14 \mathrm{ppbv}$ in that particular case) in the ice PSC, and decreases downwind. About 1 hour after the air parcels warmed up to temperatures $>T_{\text {ice }}$, depletion between $40 \%$ and $90 \%$ is found, depending on altitude.

For measurement M6, best agreement between PSC observation and theoretical data is found for water-rich LTA droplets (refractive index of 1.37) with diameters between 0.8 and $0.9 \mu \mathrm{m}$ and a number density of $9-10 \mathrm{~cm}^{-3}$. The amount of condensed $\mathrm{HNO}_{3}$ (3.4-6.5 ppbv) is similar to the value retrieved for the LTA droplets of measurement M3. However, total reduction of gas-phase $\mathrm{HNO}_{3}$ is less pronounced than in the latter case, since solid NAT particles do not contribute significantly. This is probably due to the short time span between particle nucleation and lidar observation that does not permit the NAT particles to grow to optically relevant sizes (compare Figs. 5 and 7). Finally, we note that retrieved LTA number densities of measurements M3 and M6 agree well with those reported previously (Voigt et al., 2000; Biele et al., 2001; Hu et al., 2002), while droplet diameters appear to be slightly larger (Voigt et al., 2000; Hu et al., 2002).

\section{Summary}

The clarification of the mechanisms that lead to the formation and dissipation of mountain wave-induced PSCs and the assessment of their microphysical properties will help to better understand stratospheric ozone chemistry. Our study demonstrates that ground-based lidar measurements can contribute to this endeavor if mesoscale modeling is employed to describe the meteorological setting of the observations. Only by combining the two data sets we were able to identify the 16 January 1997 mountain wave PSC event as observational evidence of NAT formation via deposition nucleation on ice particles. PSC microphysical properties were retrieved by comparison of the measured particle depolarization ratio and PSC-averaged lidar ratio to theoretical optical data obtained for different particle shapes. It is found that for relatively small particles retrieval results are stable because lidar ratio and depolarization ratio exhibit an opposite dependence on particle maximum dimension. However, this is not so with particles much larger than our observation wavelength of $355 \mathrm{~nm}$ and thus only a lower limit to the size of the PSC par- ticles can be derived in this case. The microphysical retrieval of the large PSC particles would have been improved considerably, if additionally depolarization and lidar ratios had been available at a longer wavelength, preferably at $1064 \mathrm{~nm}$.

Acknowledgements. This work was funded by grants from NASA's Atmospheric Chemistry Modeling and Analysis Program, the European Commission, and the German Bundesministerium für Bildung, Wissenschaft und Technologie. J. Reichardt would like to thank the other members of the former GKSS lidar team, R. Baumgart and A. Behrendt, and the Esrange staff for their technical support. The meteorological analysis data were available through the ECMWF special project "Effect of non-hydrostatic gravity waves on the stratosphere above Scandinavia" of one of the authors (A. Dörnbrack). The MM5 computations were performed at the German High Performance Computing Center for Climate and Earth System Research in Hamburg, Germany.

Edited by: H. Wernli

\section{References}

Ansmann, A., Wandinger, U., Riebesell, M., Weitkamp, C., and Michaelis, W.: Independent measurement of extinction and backscatter profiles in cirrus clouds by using a combined Raman elastic-backscatter lidar, Appl. Opt., 31, 7113-7131, 1992.

Baumgarten, G.: Erste Messungen des Bonner Rayleigh/Mie/Raman-Lidar auf Esrange, Schweden, zur Untersuchung von dynamisch induzierten polaren Stratosphärenwolken im Januar 1997, Diplomarbeit (Universität Bonn, Bonn, Germany), BONN-IB-97-26, 1997.

Biele, J., Tsias, A., Luo, B. P., Carslaw, K. S., Neuber, R., Beyerle, G., and Peter, T.: Nonequilibrium coexistence of solid and liquid particles in Arctic stratospheric clouds, J. Geophys. Res., 106, 22 991-23 007, 2001.

Browell, E. V., Butler, C. F., Ismail, S., Robinette, P. A., Carter, A. F., Higdon, N. S., Toon, O. B., Schoeberl, M. R., and Tuck, A. F.: Airborne lidar observations in the wintertime Arctic stratosphere: polar stratospheric clouds, Geophys. Res. Lett., 17, 385388, 1990.

Carslaw, K. S., Luo, B. P., Clegg, S. L., Peter, Th., Brimblecombe, P., and Crutzen, P. J.: Stratospheric aerosol growth and $\mathrm{HNO}_{3}$ gas phase depletion from coupled $\mathrm{HNO}_{3}$ and water uptake by liquid particles, Geophys. Res. Lett., 21, 2479-2482, 1994.

Carslaw, K. S., Wirth, M., Tsias, A., Luo, B. P., Dörnbrack, A., Leutbecher, M., Volkert, H., Renger, W., Bacmeister, J. T., and Peter, T.: Particle microphysics and chemistry in remotely observed mountain polar stratospheric clouds, J. Geophys. Res., 103, 5785-5796, 1998.

Deshler, T., Nardi, B., Adriani, A., Cairo, F., Hansen, G., Fierli, F., Hauchecorne, A., and Pulvirenti, L.: Determining the index of refraction of polar stratospheric clouds above Andoya $\left(69^{\circ} \mathrm{N}\right)$ by combining size-resolved concentration and optical scattering measurements, J. Geophys. Res., 105, 3943-3953, 2000.

Dörnbrack, A., Leutbecher, M., Kivi, R., and Kyrö, E.: Mountain wave induced record low stratospheric temperatures above northern Scandinavia, Tellus, 51A, 951-963, 1999.

Dörnbrack, A., Leutbecher, M., Reichardt, J., Behrendt, A., Müller, K.-P., and Baumgarten, G.: Relevance of mountain wave cooling 
for the formation of polar stratospheric clouds over Scandinavia: mesoscale dynamics and observations for January 1997, J. Geophys. Res., 106, 1569-1581, 2001.

Dörnbrack, A., Birner, T., Fix, A., Flentje, H., Meister, A., Schmid, H., Browell, E. V., and Mahoney, M. J.: Evidence for inertia gravity waves forming polar stratospheric clouds over Scandinavia, J. Geophys. Res., 107, D20, 8287, doi:10.1029/2001JD000452, 2002.

Dudhia, J.: A non-hydrostatic version of the Penn State-NCAR Mesoscale Model: validation tests and simulation of an Atlantic cyclone and cold front, Mon. Weather Rev., 121, 1493-1513, 1993.

Dudhia, J., Gill, D., Guo, Y.-R., Manning, K., and Wang, W.: PSU/NCAR Mesoscale Modeling System Tutorial Class Notes and User Guide: MM5 Modeling System Version 3, 2001; also at www.mmm.ucar.edu/mm5/doc.html.

Flentje, H., Dörnbrack, A., Fix, A., Meister, A., Schmid, H., Füglistaler, S., Luo, B., and Peter, T.: Denitrification inside the stratospheric vortex in the winter of 1999-2000 by sedimentation of large nitric acid trihydrate particles, J. Geophys. Res., 107, D16, doi:10.1029/2001JD001015, 2002.

Fricke, K. H.: Lee wave modification of polar stratospheric clouds at the Scandinavian mountain ridge (LWPSC), European Stratospheric Ozone Research 1996-1997, edited by Amanatidis, G. T. and Harris, N., Vol. 59, Air pollution research report, EUR 16987, 71-74, 1997.

Fricke, K. H., Müller, K. P., Serwazi, M., Reichardt, J., Kirkwood, S., Steen, Å., Hoffmann, P., Mehrtens, H., Hauchecorne, A., Fierli, F., Hoppe, U. P., and Hansen, G.: Observations of dynamically induced polar stratospheric clouds in the lee of the Scandinavian mountain ridge, Mesoscale processes in the stratosphere, Proceedings of the European workshop, edited by Carslaw, K. S. and Amanatidis, G. T., Vol. 69, Air pollution research report, EUR 18912 EN, 81-86, 1999.

Fueglistaler, S., Buss, S., Luo, B. P., Wernli, H., Flentje, H., Hostetler, C. A., Poole, L. R., Carslaw, K. S., and Peter, Th.: Detailed modeling of mountain PSCs, Atmos. Chem. Phys., 3, 697-712, 2003.

Gill, A. E: Atmosphere-Ocean Dynamics, Academic Press, New York, 1982.

Gobbi, G. P., Di Donfrancesco, G., and Adriani, A.: Physical properties of stratospheric clouds during the Antarctic winter of 1995, J. Geophys. Res., 103, 10 859-10 873, 1998.

Hanson, D. and Mauersberger, K.: Laboratory studies of the nitric acid trihydrate: implications for the south polar stratosphere, Geophys. Res. Lett., 15, 855-858, 1988.

Hess, M., Koelemeijer, R. B. A., and Stammes, P.: Scattering matrices of imperfect hexagonal ice crystals, J. Quant. Spectrosc. Radiat. Transfer, 60, 301-308, 1998.

Hu, R.-M., Carslaw, K. S., Hostetler, C., Poole, L. R., Luo, B., Peter, T., Füeglistaler, S., McGee, T. J., and Burris, J. F.: Microphysical properties of wave polar stratospheric clouds retrieved from lidar measurements during SOLVE/THESEO 2000, J. Geophys. Res., 107, D20, 8294, doi:10.1029/2001JD001125, 2002.

Krieger, U. K., Mössinger, J. C., Luo, B., Weers, U., and Peter, T.: Measurement of the refractive indices of $\mathrm{H}_{2} \mathrm{SO}_{4}-\mathrm{HNO}_{3}-\mathrm{H}_{2} \mathrm{O}$ solutions to stratospheric temperatures, Appl. Opt., 39, 36913703, 2000.

Larsen, N., Høyer Svendsen, S., Knudsen, B. M., Voigt, C., Weisser,
C., Kohlmann, A., Schreiner, J., Mauersberger, K., Deshler, T., Kröger, C., Rosen, J. M., Kjome, N. T., Adriani, A., Cairo, F., Di Donfrancesco, G., Ovarlez, J., Ovarlez, H., Dörnbrack, A., and Birner, T.: Microphysical mesoscale simulations of polar stratospheric cloud formation constrained by in situ measurements of chemical and optical cloud properties, J. Geophys. Res., 107, D20, 8301, doi:10.1029/2001JD000999, 2002.

Liu, L. and Mishchenko, M. I.: Constraints of PSC particle microphysics derived from lidar observations, J. Quant. Spectrosc. Radiat. Transfer, 70, 817-831, 2001.

Luo, B., Krieger, U. K., and Peter, T.: Densities and refractive indices of $\mathrm{H}_{2} \mathrm{SO}_{4} / \mathrm{HNO}_{3} / \mathrm{H}_{2} \mathrm{O}$ solutions to stratospheric temperatures, Geophys. Res. Lett., 23, 3707-3710, 1996.

Luo, B. P., Voigt, C., Fueglistaler, S., and Peter, T.: Extreme NAT supersaturations in mountain wave ice PSCs: a clue to NAT formation, J. Geophys. Res., 108, D15, 4441, doi:10.1029/2002JD003104, 2003.

Mishchenko, M. I.: Light scattering by randomly oriented axially symmetric particles, J. Opt. Soc. Am. A, 8, 871-882, 1991.

Müller, K.-P., Baumgarten, G., Siebert, J., and Fricke, K. H.: The new lidar facility at Esrange, Kiruna, Proceedings, 13th ESA Symposium on European Rocket and Balloon Programmes and Related Research, Öland, Sweden, 26-29 May 1997, ESA SP397, 129-134, 1997.

Reichardt, J.: Error analysis of Raman differential absorption lidar ozone measurements in ice clouds, Appl. Opt., 39, 6058-6071, 2000.

Reichardt, J., Wandinger, U., Serwazi, M., and Weitkamp, C.: Combined Raman lidar for aerosol, ozone, and moisture measurements, Opt. Eng., 35, 1457-1465, 1996.

Reichardt, J., Hess, M., and Macke, A.: Lidar inelastic multiplescattering parameters of cirrus particle ensembles determined with geometrical-optics crystal phase functions, Appl. Opt., 39, 1895-1910, 2000a.

Reichardt, J., Tsias, A., and Behrendt, A.: Optical properties of PSC Ia-enhanced at UV and visible wavelengths: model and observations, Geophys. Res. Lett., 27, 201-204, 2000b.

Reichardt, J., Reichardt, S., Behrendt, A., and McGee, T. J.: Correlations among the optical properties of cirrus-cloud particles: implications for spaceborne remote sensing, Geophys. Res. Lett., 29, doi:10.1029/2002GL014836, 2002a.

Reichardt, J., Reichardt, S., Hess, M., and McGee, T. J.: Correlations among the optical properties of cirrus-cloud particles: microphysical interpretation, J. Geophys. Res., 107, D21, 4562, doi:10.1029/2002JD002589, 2002b.

Reichardt, J., Reichardt, S., Yang, P., and McGee, T. J.: Retrieval of polar stratospheric cloud microphysical properties from lidar measurements: dependence on particle shape assumptions, J. Geophys. Res., 107, D20, 8282, doi:10.1029/2001JD001021, 2002c.

Reichardt, J., Baumgart, R., and McGee, T. J.: Three-signal method for accurate measurements of depolarization ratio with lidar, Appl. Opt., 42, 4909-4913, 2003.

Schotland, R. M., Sassen, K., and Stone, R.: Observations by lidar of linear depolarization ratios for hydrometeors, J. Appl. Meteorol., 10, 1011-1017, 1971.

Stein, B., Wedekind, C., Wille, H., Immler, F., Müller, M., Wöste, L., del Guasta, M., Morandi, M., Stefanutti, L., Antonelli, A., Agostini, P., Rizi, V., Readelli, G., Mitev, V., Matthey, R., 
Kivi, R., and Kyrö, E.: Optical classification, existence temperatures, and coexistence of different polar stratospheric cloud types, J. Geophys. Res., 104, 23 983-23 993, 1999.

Tabazadeh, A., Toon, O. B., and Jensen, E. J.: Formation and implications of ice particle nucleation in the stratosphere, Geophys. Res. Lett., 24, 2007-2010, 1997.

Tsias, A., Wirth, M., Carslaw, K. S., Biele, J., Mehrtens, H., Reichardt, J., Wedekind, C., Weiß, V., Renger, W., Neuber, R., von Zahn, U., Stein, B., Santacesaria, V., Stefanutti, L., Fierli, F., Bacmeister, J., and Peter, T.: Aircraft lidar observations of an enhanced type Ia polar stratospheric cloud during APE-POLECAT, J. Geophys. Res., 104, 23 961-23 969, 1999.

Toon, O. B., Tabazadeh, A., Browell, E. V., and Jordan, J.: Analysis of lidar observations of Arctic polar stratospheric clouds during January 1989, J. Geophys. Res., 105, 20 589-20 615, 2000.

van de Hulst, H. C.: Light Scattering by Small Particles, Dover, New York, 1981.

Voigt, C., Schreiner, J., Kohlmann, A., Zink, P., Mauersberger, K., Larsen, N., Deshler, T., Kröger, C., Rosen, J., Adriani, A., Cairo,
F., Di Donfrancesco, G., Viterbini, M., Ovarlez, J., Ovarlez, H., David, C., and Dörnbrack, A.: Nitric acid trihydrate (NAT) in polar stratospheric clouds, Science, 290, 1756-1758, 2000.

Wandinger, U.: Multiple-scattering influence on extinction- and backscatter-coefficient measurements with Raman and highspectral-resolution lidars, Appl. Opt., 37, 417-427, 1998.

Warren, S. G.: Optical constants of ice from the ultraviolet to the microwave, Appl. Opt., 23, 1206-1225, 1984.

Wirth, M., Tsias, A., Dörnbrack, A., Weiß, V., Carslaw, K. S., Leutbecher, M., Renger, W., Volkert, H., and Peter, T.: Model-guided Lagrangian observation and simulation of mountain polar stratospheric clouds, J. Geophys. Res., 104, 23 971-23 981, 1999.

Yang, P., Liou, K. N., Mishchenko, M. I., and Gao, B.-C.: Efficient finite-difference time-domain scheme for light scattering by dielectric particles: application to aerosols, Appl. Opt., 39, 37273737, 2000.

Zängl, G.: Stratified flow over a mountain with a gap: linear theory and numerical simulations, Q. J. R. Meteorol. Soc., 128, 927949, 2002. 